\title{
State-Space Model of Grid-Connected Inverters under Current Control Mode
}

\author{
N. Kroutikova, C.A. Hernandez-Aramburo and T.C. Green \\ Department of Electrical and Electronic Engineering, Imperial College London \\ London, United Kingdom, SW7 2BT
}

\begin{abstract}
The growth of distributed generation has led to distribution systems with a mixture of rotating machine generators and inverter interfaced generators. The stability of such networks needs to be studied through analysis of state-space models and so suitable models of inverters are needed to complement the well established models of rotating machines. Just as machine models include features such as automatic voltage regulators and wash-out functions so too should the inverter model include phase-locking functions and internal control loops. This paper develops the model for voltage source inverters with an internal current control loop, an outer power regulation loop, a measurement of average power and a phase-locked loop. The model is presented in detail and is formed with a state-vector similar to that used for rotating machines. The model includes non-linear terms but can be linearised about an operating point. The state-space model is verified against a component-level time-step simulation in Simulink/PLECS.
\end{abstract}

\section{Introduction}

Many of the forms of new and renewable energy are not natural 50 or $60 \mathrm{~Hz}$ sources and the question arises of how to incorporate them into a standard electricity grid. Most of this technology (PV panels, high-speed micro-turbines, fuel cells) has an inverter as a generator interface. That inverter can operate either as a current source or as a voltage source. In either case, the implementation will normally be a voltage source inverter (VSI) and appropriate control loops will be added to make it appear as a controlled current source if necessary. The inverter will be fitted with a coupling impedance and possibly further passive filter elements to attenuate the switching frequency components of voltage. The inverter will also require a means to measure exported power. The inverter must also be explicitly phase-locked through a phase-locked loop or implicitly phase-locked through droop regulation. Thus the inverter is a complex dynamic system which interacts with the grid. In some circumstances it will be necessary to establish the stability limits of the inverter and grid combination. For traditional generators such as synchronous machines and induction (asynchronous) machines there are well established dynamic models, and for each type of stability study (covering various frequency ranges and types of interaction) an appropriate model can be selected that includes all of the necessary machine features and has a standard state vector. Many years of experience and design standardisation has led to the situation where power systems engineers know which features 
and modes must be include in each type of study. Inverter-interfaced generators are not yet that mature and the modelling of inverters for network stability studies requires much more work if grid stability is to be ensured with high penetrations of distributed generation.

Component-level models (Spice-based simulators for example) allow the evaluation of inverter performance during every switching action [1]. Applications at this level of simulation detail include the calculation of switching losses and the testing of snubber networks [2]. This simulation approach offers an accurate representation of the system in the time domain but it can be very time consuming to perform over the duration of a power frequency oscillation. Another approach to simulate the switching action of the power devices is to use the principle of switching functions $[3,4]$. A disadvantage of this approach is that the switching instants of the devices must be known in advance. At the other end of the spectrum (in terms of the simulation detail to be used), there are applications where modelling the whole inverter system as a simple voltage gain is good enough. In these applications the inverter is normally a small part of a large system and the dynamics of the inverter have a small impact on the overall system.

Inverters are sometimes modelled in a space-state formulation with the power devices in the inverter represented as ideal switches [5]. Under this assumption some accuracy is lost but the simulation time is normally improved by reducing both the time required by an analyst to set up a simulation and the time taken by a computer to produce the result. Space-state modelling of power converters is well documented in textbooks [6] and it has been used to simulate many different types of power converter. A common simplification is to linearise the switching circuit by creating a small-signal model and to consider the average behaviour of the switched circuit over a period. A small sample of the literature includes: DC/DC converters [7], AC/DC converters [8-10], DC/AC converters [11-14] and FACTS devices [15].

Despite the modelling efforts to date, better VSI models are still needed for studies of DG integration. The model must represent all of the dynamics of the inverter in the frequency range of interest and allow coupling to reasonable models of the distribution network. Models of voltage source inverters for grid connection normally include the low pass (LC-based) filter required to attenuated switching frequency noise and the coupling impedance between the filter and connection node in the distribution network. A complete model should also include the control system associated with the converter circuit [16-20]. This includes the phase-lock loop, the $a b c$-to- $d q$ transformations, the controllers for current and voltage and any low-pass filters applied to feedback or control signals (such as used to obtain average power from instantaneous power or to attenuate noise in measured signals).

This paper presents a model of a three-phase inverter system including a complete set of the sub-systems 
required for interfacing a DG source to a grid. The model is for current-control mode, which is one of the two main operation modes relevant to Distributed Generation. A companion paper [21] develops models for inverters operated in droop-regulated controlled-voltage mode. The models are presented in detail so that the meaning of the various parameters can be understood and can be related to features of real inverters. Thus, models of inverters can be made available in standard form. The validation of the model is carried out by comparing waveforms generated from the state-space model with those from a component level simulation in Simulink/PLECS.

The intended contribution of this paper is to provide verified models of inverter interfaced generators to be used by the wider community in studying interactions between inverters and the power system to which they are connected.

\section{VSI in current control mode}

In situations where a strong network connection is available, that is, a connection point with an already tightly regulated voltage and frequency, it is common to export power into that connection through setting a current reference for the inverter. That reference can represent any combination of real and reactive power. The exported power will not significantly influence the voltage or frequency at the point of connection. A schematic of an inverter arranged in current-controlled mode is shown in fig. 1 and follows the proposal made in [22]. The objective is to regulate real and reactive power to follow reference values $\left(P^{*}\right.$ and $\left.Q^{*}\right)$. The power references and the voltages at the point of connection $\left(v_{O a}, v_{O b}\right.$, and $\left.v_{O c}\right)$ are used to set references for the current controllers. The inverter is provided with a DC link voltage $\left(V_{D C}\right)$ from the original energy source. These variables constitute the inputs to the model. The output variables of direct interest are the output currents $\left(i_{O a}, i_{O b}\right.$ and $\left.i_{O c}\right)$. It might also be desirable to monitor the alignment angle of the phase-locked loop (PLL) or, if the model is to be coupled to a model of the energy source, the DC link current $\left(i_{D C}\right)$ can be arranged as an output. Fig. 1 shows that control is performed in a rotating reference frame (th $d q$-domain) and the reference angle for the $a b c-d q$ transformation is provided by the PLL. The inverter output is shown with a second-order LC element and an additional inductor for coupling to the connection point. The output current $\left(i_{O d q}\right)$ is therefore equal to the current in the filter inductor minus the current in the shunt-connected capacitor of the filter. It is the inductor current $i_{L}$ which is controlled to follow the reference current (in turn determined by the power references) [23]. It is assumed that the current in the filter capacitor is of high frequency and in terms of power export at fundamental frequency, the inductor and output currents are essentially identical. Other variables shown in fig. 1 will be discussed in detail as the paper 
progresses.

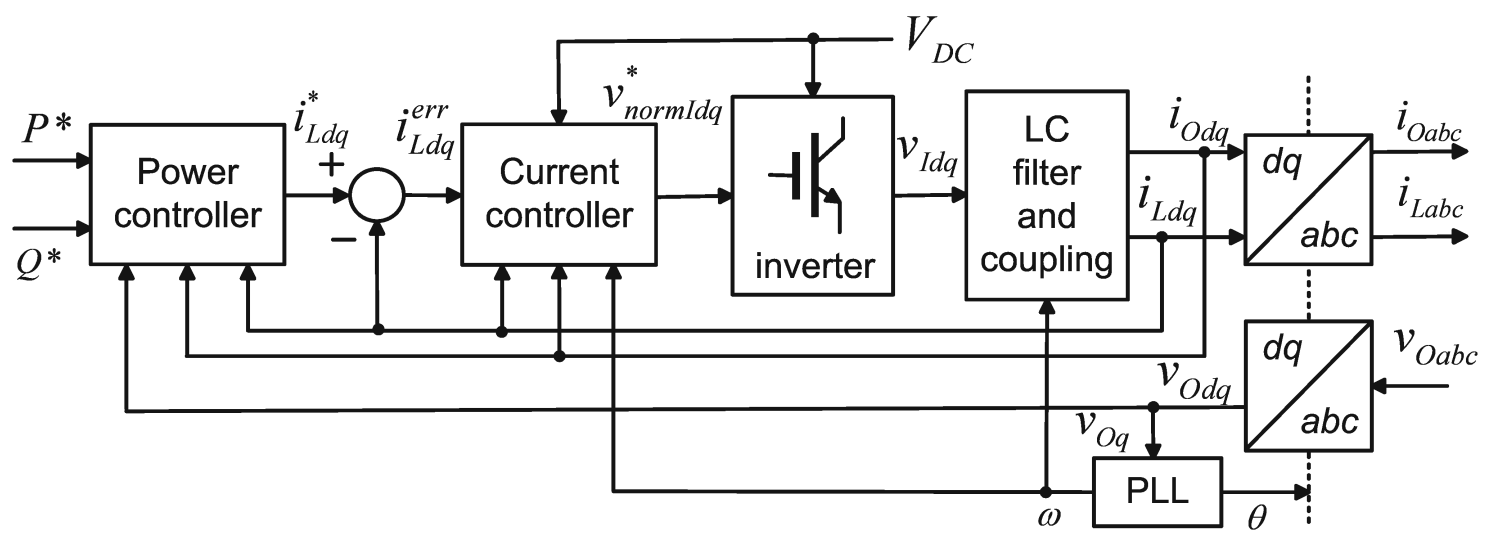

Figure 1: Model of a current-controlled VSI

The objective is to build a single state-space model for all of the elements shown in fig. 1 such that the dynamics of both the power processing elements and the associated local controls are included. This model will be of the form described by (1), which is a state-space form that allows nonlinear functions of $x$ and $u$ to be included. To accomplish this goal, in the following sub-sections a state-space model is derived for each sub-system. The sub-system models are then arranged into a complete model and duplicate variables eliminated.

$$
\begin{aligned}
\dot{x} & =A x+R(x, u) \\
y & =S(x, u)
\end{aligned}
$$

\subsection{State-Space Model of the $d q-a b c$ Transformation}

The first subsystem in the inverter topology is the $d q$-to- $a b c$ transformation is defined by (2).

$$
\left[\begin{array}{c}
i_{O a} \\
i_{O b} \\
i_{O c}
\end{array}\right]=\sqrt{\frac{2}{3}}\left[\begin{array}{ccc}
\cos \theta & -\sin \theta & \frac{1}{\sqrt{2}} \\
\cos \left(\theta-\frac{2 \pi}{3}\right) & -\sin \left(\theta-\frac{2 \pi}{3}\right) & \frac{1}{\sqrt{2}} \\
\cos \left(\theta+\frac{2 \pi}{3}\right) & -\sin \left(\theta+\frac{2 \pi}{3}\right) & \frac{1}{\sqrt{2}}
\end{array}\right]\left[\begin{array}{c}
i_{O d} \\
i_{O q} \\
i_{O O}
\end{array}\right]
$$

The angle of the rotational frame is treated as an input to this subsystem and there are no state variables. Equation 2 represents a feed-through term from input to output and no state-vector is needed:

$$
\dot{x}_{1}=[0]
$$




\subsection{State-Space Model of the Phase Lock Loop System}

The PLL system indicated in fig. 1 is shown in more detail in fig. 2.

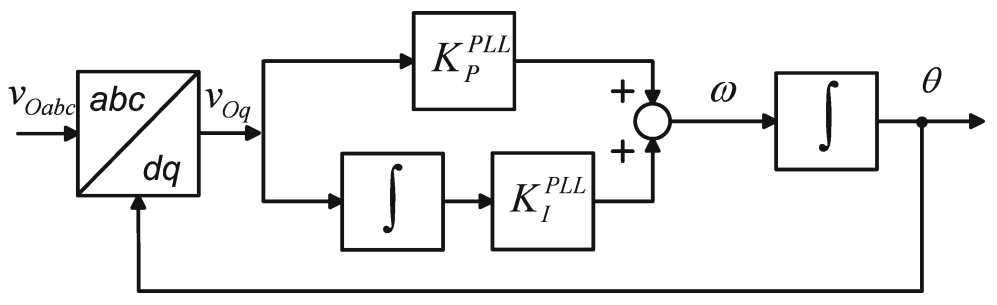

Figure 2: Model for the PLL

The $a b c$-to- $d q$ transformation is defined by (4).

$$
\left[\begin{array}{c}
v_{O d} \\
v_{O q} \\
v_{O_{O}}
\end{array}\right]=\sqrt{\frac{2}{3}}\left[\begin{array}{rrr}
\cos \theta & \cos \left(\theta-\frac{2 \pi}{3}\right) & \cos \left(\theta+\frac{2 \pi}{3}\right) \\
-\sin \theta & -\sin \left(\theta-\frac{2 \pi}{3}\right) & -\sin \left(\theta+\frac{2 \pi}{3}\right) \\
\frac{1}{\sqrt{2}} & \frac{1}{\sqrt{2}} & \frac{1}{\sqrt{2}}
\end{array}\right]\left[\begin{array}{c}
v_{O a} \\
v_{O b} \\
v_{O c}
\end{array}\right]
$$

In this paper it is assumed that there is no path for the zero sequence components, therefore $i_{O_{O}}$ in $(2)$ and $v_{O_{O}}$ in (4) could be ignored. However, these variables are left in the formulation to pave the way for a more general case.

The PLL form adopted here is based on aligning in closed-loop control the angle of the $d q$-transformation such that the voltage at the connection point has no $q$-axis component [24]. A PI regulator acts on the alignment error to set the rotation frequency, (5), and that frequency is integrated to give the transformation angle, (6).

$$
\begin{gathered}
\omega=K_{P}^{P L L} v_{O q}+K_{I}^{P L L} \int v_{O q} \mathrm{~d} t \\
\theta=\int \omega \mathrm{d} t
\end{gathered}
$$

To express (5) in a purely differential form, an additional variable is defined: $\Phi_{P L L}=\int v_{O q} \mathrm{~d} t$. This variable does not have a particular physical meaning but it facilitates the development of the state-space model (and has the same dimensions as magnetic flux). The additional variable is part of the state-vector together with $\theta$ (taken from (6)): $x_{2}=\left[\begin{array}{ll}\theta & \Phi_{P L L}\end{array}\right]^{T}$. The input variable to the PLL is $u_{2}=\left[\begin{array}{ccc}v_{O a} & v_{O b} & v_{O c}\end{array}\right]^{T}$ and the output, which includes the $d q$ transformation, is $y_{2}=\left[\begin{array}{lll}\theta & v_{O d} & v_{O q}\end{array}\right]^{T}$.

With the definitions above, the state-space model of PLL loop can then be written in the form $\dot{x}_{2}=A_{2} x_{2}+$ $R_{2}\left(x_{2}, u_{2}\right)$ as follows: 


$$
\dot{x}_{2}=\left[\begin{array}{cc}
0 & K_{I}^{P L L} \\
0 & 0
\end{array}\right]\left[\begin{array}{c}
\theta \\
\Phi_{P L L}
\end{array}\right]+\left[\begin{array}{c}
K_{P}^{P L L} v_{O q} \\
v_{O q}
\end{array}\right]
$$

where $v_{O q}$ is given in (4) and is a multiplication of state $\theta$ with input $v_{O a b c}$.

\subsection{State-Space Model of the Power Controller}

The power controller is not a closed-loop controller but instead is an open-loop conversion of a power reference into a current reference given the prevailing voltage at the point of connection. The current is then controlled in closed-loop as discussed in the next section. This subsystem is non-linear because of the need to divide power by voltage to obtain current and it contains higher-order dynamics because of the filter employed. The sub-system is illustrated in fig. 3 .

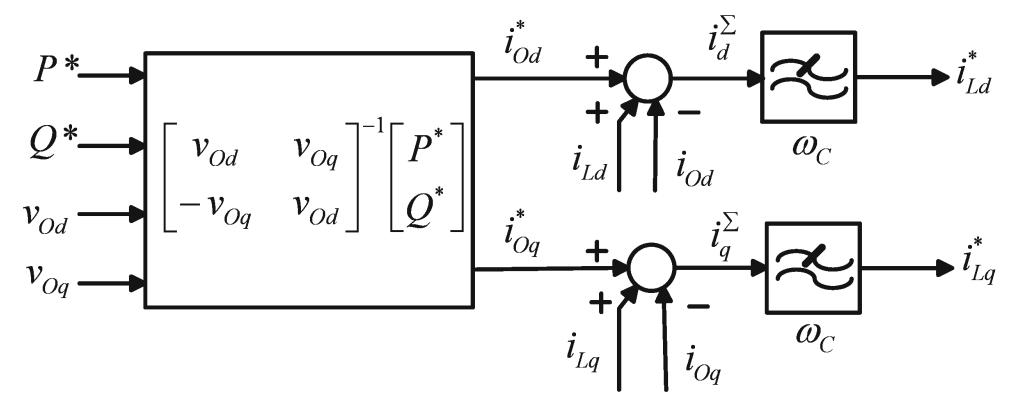

Figure 3: Power controller [22]

The desired output currents are calculated using the following pair of equations:

$$
i_{O d}^{*}=\frac{v_{O d} P^{*}-v_{O q} Q^{*}}{v_{O d}^{2}+v_{O q}^{2}}, \quad i_{O q}^{*}=\frac{v_{O q} P^{*}+v_{O d} Q^{*}}{v_{O d}^{2}+v_{O q}^{2}}
$$

It is actually the filter inductor current that is controlled and so an adjustment must be made to the reference to account for the capacitor current. This is performed using the measured inductor current and measured output current:

$$
\begin{aligned}
& i_{d}^{\Sigma}=i_{O d}^{*}+i_{C d}=i_{O d}^{*}+\left(i_{L d}-i_{O d}\right), \\
& i_{q}^{\Sigma}=i_{O q}^{*}+i_{C q}=i_{O q}^{*}+\left(i_{L q}-i_{O q}\right)
\end{aligned}
$$

These current references might contain harmonic and noise terms as a consequence of distortion of the voltage at the point of connection. These are removed from the reference by a low pass filter. Because of the relatively low cut-off frequency required of this filter it can make an important contribution to the dynamics of the system and should be included in the model. A second-order Butterworth low-pass transfer function is taken as representative 
of the filter likely to be used. Equation (10) shows the references for the current controllers, $i_{L d}^{*}$ and $i_{L q}^{*}$, formed by the product of a generic filter and the terms in (9):

$$
i_{L d}^{*}=\frac{\omega_{c}^{2}}{s^{2}+\sqrt{2} s \omega_{c}+\omega_{c}^{2}} i_{d}^{\Sigma}, \quad i_{L q}^{*}=\frac{\omega_{c}^{2}}{s^{2}+\sqrt{2} s \omega_{c}+\omega_{c}^{2}} i_{q}^{\Sigma}
$$

Equation (10) can be re-arranged as in (11) and then rewritten in integro-differential form as in (12).

$$
\begin{gathered}
i_{L d}^{*} s+i_{L d}^{*} \sqrt{2} \omega_{c}+i_{L d}^{*} \frac{1}{s} \omega_{c}^{2}=\frac{1}{s} \omega_{c}^{2} i_{d}^{*} \\
i_{L q}^{*} s+i_{L q}^{*} \sqrt{2} \omega_{c}+i_{L q}^{*} \frac{1}{s} \omega_{c}^{2}=\frac{1}{s} \omega_{c}^{2} i_{q}^{*} \\
\frac{\mathrm{d} i_{L d}^{*}}{\mathrm{~d} t}=\omega_{c}^{2} \int\left(i_{d}^{\Sigma}-i_{L d}^{*}\right) \mathrm{d} t-\omega_{c} \sqrt{2} i_{L d}^{*}=\omega_{c}^{2} q_{3 d}-\omega_{c} \sqrt{2} i_{L d}^{*} \\
\frac{\mathrm{d} i_{L q}^{*}}{\mathrm{~d} t}=\omega_{c}^{2} \int\left(i_{q}^{\Sigma}-i_{L q}^{*}\right) \mathrm{d} t-\omega_{c} \sqrt{2} i_{L q}^{*}=\omega_{c}^{2} q_{3 q}-\omega_{c} \sqrt{2} i_{L q}^{*}
\end{gathered}
$$

Equations (8), (9) and (12) together describe the power controller. They can be assembled into state-space form by introducing new variables for the integrals in (12). Since these are integrations of current, the new variables are denoted as charges: $q_{3 d}=\int\left(i_{d}^{\Sigma}-i_{L d}^{*}\right) \mathrm{d} t$ and $q_{3 q}=\int\left(i_{q}^{\Sigma}-i_{L q}^{*}\right) \mathrm{d} t$. The state-variable is then $x_{3}=$

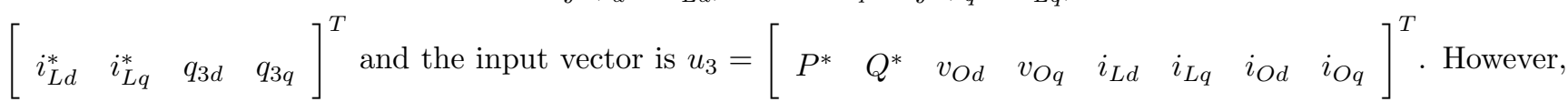
because of the form of (8), the inputs can not be included as linear terms into the state-space model of the system; and therefore this model takes the form $\dot{x}_{3}=A_{3} x_{3}+R_{3}\left(u_{3}\right)$. The full equation is as follows:

$$
\dot{x}_{3}=\left[\begin{array}{cccc}
-\sqrt{2} \omega_{c} & 0 & \omega_{c}^{2} & 0 \\
0 & -\sqrt{2} \omega_{c} & 0 & \omega_{c}^{2} \\
-1 & 0 & 0 & 0 \\
0 & -1 & 0 & 0
\end{array}\right]\left[\begin{array}{c}
i_{L d}^{*} \\
i_{L q}^{*} \\
q_{3 d} \\
q_{3 q}
\end{array}\right]+R_{3}\left(u_{3}\right)
$$

Where $R_{3}\left(u_{3}\right)$ is the nonlinear function of the input variables:

$$
R_{3}\left(u_{3}\right)=\left[\begin{array}{c}
0 \\
0 \\
i_{d}^{\Sigma} \\
i_{q}^{\Sigma}
\end{array}\right]=\left[\begin{array}{c}
0 \\
0 \\
\frac{v_{O d} P^{*}-v_{O q} Q^{*}}{v_{O d}^{2}+v_{O q}^{2}}+i_{L d}-i_{O d} \\
\frac{v_{O q} P^{*}+v_{O d} Q^{*}}{v_{O d}^{2}+v_{O q}^{2}}+i_{L q}-i_{O q}
\end{array}\right]
$$

The output vector for the power regulator is composed of the two reference currents:

$y_{3}=\left[\begin{array}{ll}i_{L d}^{*} & i_{L q}^{*}\end{array}\right]$. 


\subsection{State-Space Model of the Current Controller}

The current controller indicated in fig. 1 is implemented as a pair of $P I$ controllers together with cross-axis decoupling terms and feed-forward terms for the connection voltage. Because the inverter represents (on average) a gain equal to the DC link voltage, it is desirable to include a division by the DC link voltage so that the inverter remains a normalised gain term even if the DC link voltage varies. The controller block diagram is shown in fig. 4 .

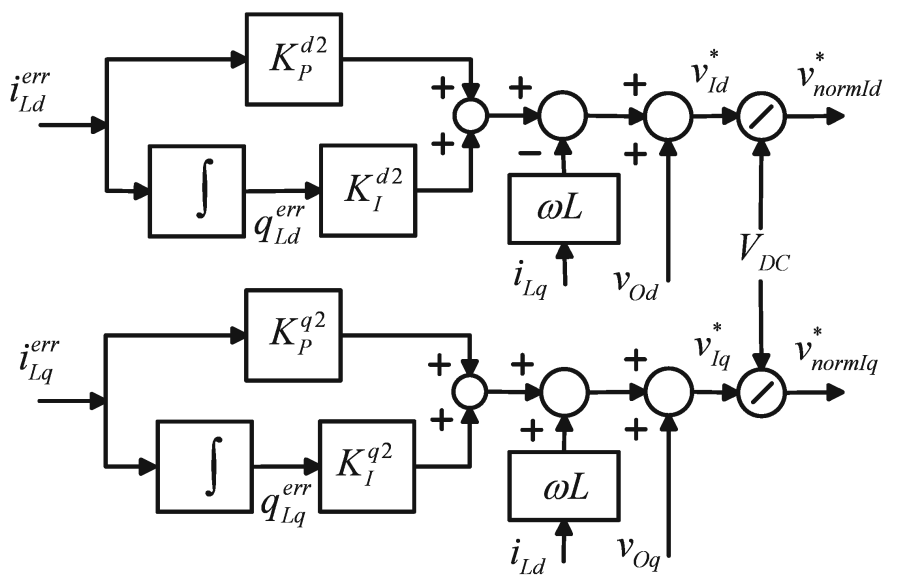

Figure 4: Model for the current controller

From fig. 4, the following equations can be obtained:

$$
\begin{aligned}
& v_{I d}^{*}=v_{O d}-\omega L i_{L q}+K_{P}^{d 2} i_{L d}^{e r r}+K_{I}^{d 2} \int i_{L d}^{e r r} \mathrm{~d} t \\
& v_{I q}^{*}=v_{O q}+\omega L i_{L d}+K_{P}^{q 2} i_{L q}^{e r r}+K_{I}^{q 2} \int i_{L q}^{e r r} \mathrm{~d} t
\end{aligned}
$$

The frequency $(\omega)$ is taken from the PLL and is treated as an input here.

Once again, new variables are introduced to obtain the state space model: $q_{L d}^{e r r}=\int i_{L d}^{e r r} \mathrm{~d} t$ and $q_{L q}^{e r r}=\int i_{L q}^{e r r} \mathrm{~d} t$. The state and input vectors of the current controller are given by (17) and (18), respectively.

$$
\begin{aligned}
& x_{4}=\left[\begin{array}{ll}
q_{L d}^{\mathrm{err}} & q_{L q}^{\mathrm{err}}
\end{array}\right]^{T} \\
& u_{4}=\left[\begin{array}{lllllll}
i_{L d}^{\mathrm{err}} & i_{L q}^{\mathrm{err}} & i_{L d} & i_{L q} & v_{O d} & v_{O q} & \omega
\end{array}\right]^{T}
\end{aligned}
$$

The state-space model is in standard linear form, $\dot{x}_{4}=A_{4} x_{4}+B_{4} u_{4}$, but because the two new states of this subsystem do not involve internal feedback, the $A$ matrix is zero. The model is given in (19). 


$$
\dot{x}_{4}=\left[\begin{array}{ll}
0 & 0 \\
0 & 0
\end{array}\right]\left[\begin{array}{c}
q_{L d}^{\mathrm{err}} \\
q_{L q}^{\mathrm{err}}
\end{array}\right]+\left[\begin{array}{ccccccc}
1 & 0 & 0 & 0 & 0 & 0 & 0 \\
0 & 1 & 0 & 0 & 0 & 0 & 0
\end{array}\right]\left[\begin{array}{c}
i_{L d}^{e r r} \\
i_{L q}^{e r r} \\
i_{L d} \\
i_{L q} \\
v_{O d} \\
v_{O q} \\
\omega
\end{array}\right]
$$

The output equation is in standard form except for the division by the DC link voltage:

$$
\begin{gathered}
y_{4}=\frac{1}{v_{D C}}(C x+D u+S(u)) \\
y_{4}=\frac{1}{v_{D C}}\left(\left[\begin{array}{cc}
K_{I}^{d 2} & 0 \\
0 & K_{I}^{q 2}
\end{array}\right]\left[\begin{array}{c}
q_{L d}^{\text {err }} \\
q_{L q}^{\text {err }}
\end{array}\right]+\left[\begin{array}{ccccccc}
K_{P}^{d 2} & 0 & 0 & 0 & 1 & 0 & 0 \\
0 & K_{P}^{q 2} & 0 & 0 & 0 & 1 & 0
\end{array}\right]\left[\begin{array}{c}
i_{L d}^{e r r} \\
i_{L q}^{e r r} \\
i_{L d} \\
i_{L q} \\
v_{O d} \\
v_{O q} \\
\omega
\end{array}\right]+\left[\begin{array}{c}
-\omega L i_{L q} \\
\omega L i_{L d}
\end{array}\right]\right)
\end{gathered}
$$

\subsection{State-Space Model of the Inverter}

The inverter itself is a switch-mode circuit and for the purpose of this model development it is assumed that the switching frequency is sufficiently high that the switching action itself does no affect the evolution of the states and state-space averaging can be applied. In other words, the switching frequency ripple of states such as the inductor currents can be ignored without significantly affecting the accuracy with which the average inductor current is predicted. It is expected that the passive low-pass filter at the output of the inverter will have been chosen to attenuate switching frequency ripple to acceptable levels. As switching frequencies of commercial DG inverters continue to improve, this approximation becomes better. There may be some high power inverters with low switching frequencies (less than $1 \mathrm{kHz}$ ) where the physical size and the cost of the filter have been constrained and where the state-space averaging assumptions are not strictly valid.

With the switching action of the inverter neglected, the model of the inverter can be simplified to a saturated voltage gain, as shown in fig. 5 . 


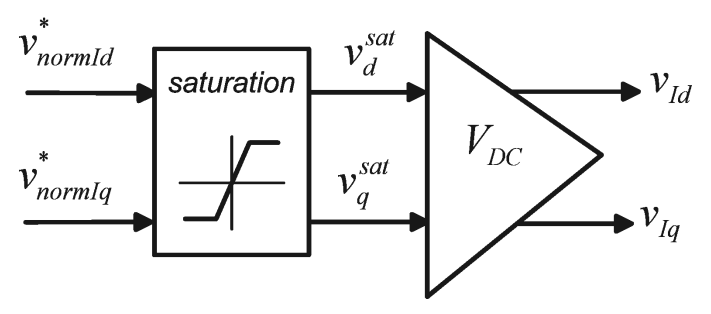

Figure 5: Simplified model of the inverter

Saturation arises because there is a finite DC-link voltage which in turn producesa magnitude-constrained AC voltage at the output. Because the saturation function is a non-linear element, it is not included in the linear differential equations. Voltage saturation is, however, an important characteristic of VSI and it should be modelled in time-step simulations used to verify results from linearized $s$-domain models. Saturation can be included in time-step simulations with if-then-else commands, as shown table 1.

Table 1: Computer-based model of saturation

\begin{tabular}{|c|}
\hline Saturation \\
\hline if $\left(v_{\text {normId }}^{*}\right)^{2}+\left(v_{\text {normId }}^{*}\right)^{2} \geq \frac{1}{2}$ \\
$\theta=\tan ^{-1} \frac{v_{\text {normI } q}^{*}}{v_{\text {normId }}^{*}}$ \\
$v_{d}^{\text {sat }}=\frac{1}{\sqrt{2}} \cos (\theta)$ \\
$v_{q}^{\text {sat }}=\frac{1}{\sqrt{2}} \sin (\theta)$ \\
else $v_{d}^{\text {sat }}=v_{\text {normId }}^{*}$ \\
$v_{q}^{\text {sat }}=v_{\text {normIq }}^{*}$ \\
end \\
\hline
\end{tabular}

The voltage gain model of the VSI in state-space variables is simply:

$$
\dot{x}_{5}=[0]
$$

The output is $y_{5}=\left[\begin{array}{ll}v_{I d} & v_{I q}\end{array}\right]$

\subsection{State-Space Model of LC Filter and Coupling Impedance}

Although the switching frequency ripple has been dismissed from the model, the passive low-pass filter must still be included in the model. The selection of the inductors and capacitors of this filter involves some design compromise and the filter will have important dynamic effects down to quite low frequencies. This sub-system includes both the coupling inductance that is always present and any additional filter components. The coupling impedance might 
in reality be a coupling inductor or the leakage impedance of a coupling transformer. If this is indeed a coupling inductor the $L C$ filter becomes a $L C L$ filter. How to design the output filters is out of the scope of this paper; detailed analyses of these filters can be found in $[25,26]$.

The $L C$ filter (assumed symmetric)in the $a b c$ reference frame is shown in fig. 6 .

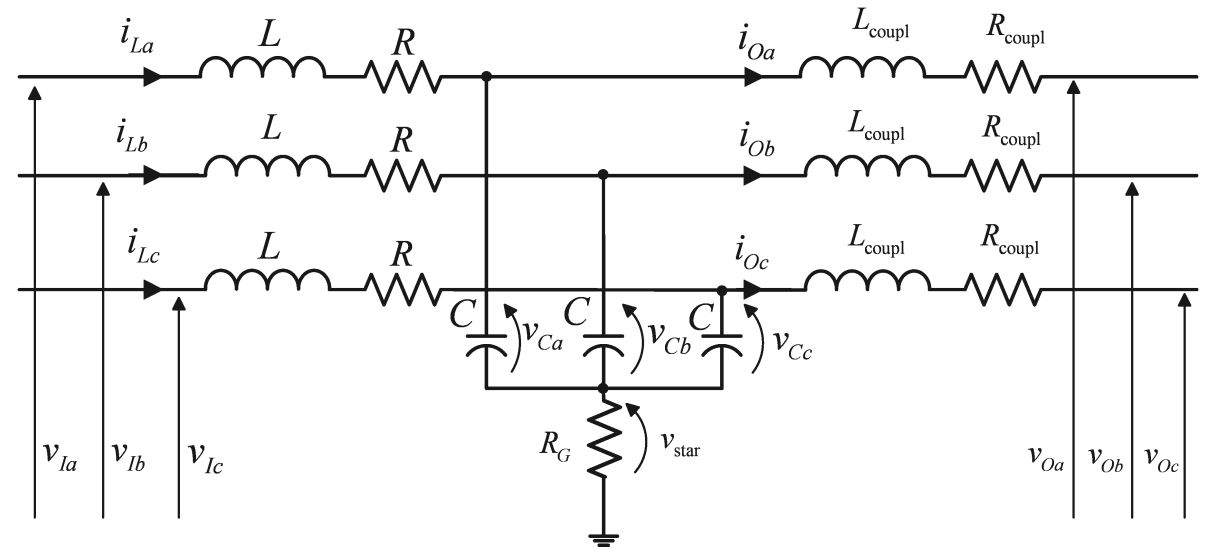

Figure 6: LC filter and load

The equations describing phase $a$ of the filter are presented in (22) to (24).

$$
\begin{gathered}
v_{I a}=i_{L a} R+L \frac{\mathrm{d} i_{L a}}{\mathrm{~d} t}+v_{C a}+v_{\text {star }} \\
v_{O a}=v_{C a}+v_{\text {star }}-L_{\text {coupl }} \frac{\mathrm{d} i_{O a}}{\mathrm{~d} t}-i_{O a} R_{\text {coupl }} \\
C \frac{\mathrm{d} v_{C a}}{\mathrm{~d} t}=i_{L a}-i_{O a} \\
v_{\text {star }}=3 R_{G}\left(i_{L a}-i_{O a}\right)
\end{gathered}
$$

To create a general filter model, the star-point of the capacitors is connected to ground by an impedance. Selecting a low value impedance would model a four-wire filter and a high value impedance would model a threewire filter. The input, output and state vectors of the filter in $d q$ form are:

$$
\begin{aligned}
& u_{6}=\left[\begin{array}{lllllll}
v_{I d} & v_{I q} & v_{I_{O}} & v_{O_{d}} & v_{O_{q}} & v_{O_{O}} & \omega
\end{array}\right]^{T} \\
& y_{6}=\left[\begin{array}{llllll}
i_{L d} & i_{L q} & i_{L_{O}} & i_{O d} & i_{O q} & i_{O_{O}}
\end{array}\right]^{T} \\
& x_{6}=\left[\begin{array}{lllllllll}
i_{L d} & i_{L q} & i_{L_{O}} & v_{C d} & v_{C q} & v_{C_{O}} & i_{O d} & i_{O q} & i_{O_{O}}
\end{array}\right]^{T}
\end{aligned}
$$

The matrices $A_{6}, B_{6}$ and $R_{6}$ in the state-space model $\dot{x}_{6}=A_{6} x_{6}+B_{6} u_{6}+R_{6}\left(x_{6}, u_{6}\right)$ are found to be: 


$$
\begin{gathered}
A_{6}=\left[\begin{array}{ccccccccc}
\frac{-R}{L} & 0 & 0 & \frac{-1}{L} & 0 & 0 & 0 & 0 & 0 \\
0 & \frac{-R}{L} & 0 & 0 & \frac{-1}{L} & 0 & 0 & 0 & 0 \\
0 & 0 & \frac{-3 R_{G}-R}{L} & 0 & 0 & \frac{-1}{L} & 0 & 0 & \frac{3 R_{G}}{L} \\
\frac{1}{C} & 0 & 0 & 0 & 0 & 0 & \frac{-1}{C} & 0 & 0 \\
0 & \frac{1}{C} & 0 & 0 & 0 & 0 & 0 & \frac{-1}{C} & 0 \\
0 & 0 & \frac{1}{C} & 0 & 0 & 0 & 0 & 0 & \frac{-1}{C} \\
0 & 0 & 0 & \frac{1}{L_{\text {coupl }}} & 0 & 0 & \frac{-R_{\text {coupl }}}{L_{\text {coupl }}} & 0 & 0 \\
0 & 0 & 0 & 0 & \frac{1}{L_{\text {coup }}} & 0 & 0 & \frac{-R_{\text {coupl }}}{L_{\text {coupl }}} \\
0 & 0 & 0 & 0 & 0 & \frac{3 R_{G}}{L_{\text {coupl }}} & 0 & 0 & \frac{-3 R_{G}-R_{\text {coupl }}}{L_{\text {coupl }}}
\end{array}\right] \\
B_{6}=\left[\begin{array}{ccccccc}
\frac{1}{L} & 0 & 0 & 0 & 0 & 0 & 0 \\
0 & \frac{1}{L} & 0 & 0 & 0 & 0 & 0 \\
0 & 0 & \frac{1}{L} & 0 & 0 & 0 & 0 \\
0 & 0 & 0 & 0 & 0 & 0 & 0 \\
0 & 0 & 0 & 0 & 0 & 0 & 0 \\
0 & 0 & 0 & 0 & 0 & 0 & 0 \\
0 & 0 & 0 & \frac{-1}{L_{\text {coupl }}} & 0 & 0 & 0 \\
0 & 0 & 0 & 0 & \frac{-1}{L_{\text {coupl }}} & 0 & 0 \\
0 & 0 & 0 & 0 & 0 & \frac{-1}{L_{\text {coupl }}} & 0
\end{array}\right], \quad R_{6}=\left[\begin{array}{c}
\omega i_{L q} \\
-\omega i_{L d} \\
0 \\
\omega v_{C q} \\
-\omega v_{C d} \\
0 \\
\omega i_{O q} \\
-\omega i_{o d} \\
0
\end{array}\right]
\end{gathered}
$$

The output matrix is:

$$
C_{6}=\left[\begin{array}{lllllllll}
1 & 0 & 0 & 0 & 0 & 0 & 0 & 0 & 0 \\
0 & 1 & 0 & 0 & 0 & 0 & 0 & 0 & 0 \\
0 & 0 & 1 & 0 & 0 & 0 & 0 & 0 & 0 \\
0 & 0 & 0 & 0 & 0 & 0 & 1 & 0 & 0 \\
0 & 0 & 0 & 0 & 0 & 0 & 0 & 1 & 0 \\
0 & 0 & 0 & 0 & 0 & 0 & 0 & 0 & 1
\end{array}\right]
$$

\section{Complete Model}

Fig. 7 is a redrawing of fig. 1 but with the state variables of each sub-system identified ready to form the overall model of a Current Controlled Inverter (CCI) that was envisaged in (1). The inputs of the system can readily be assembled into the input vector $(u)$ given by (29).

$$
u_{\mathrm{CCI}}=\left[\begin{array}{llllll}
V_{D C} & v_{O a} & v_{O b} & v_{O c} & P^{*} & Q^{*}
\end{array}\right]^{T}
$$




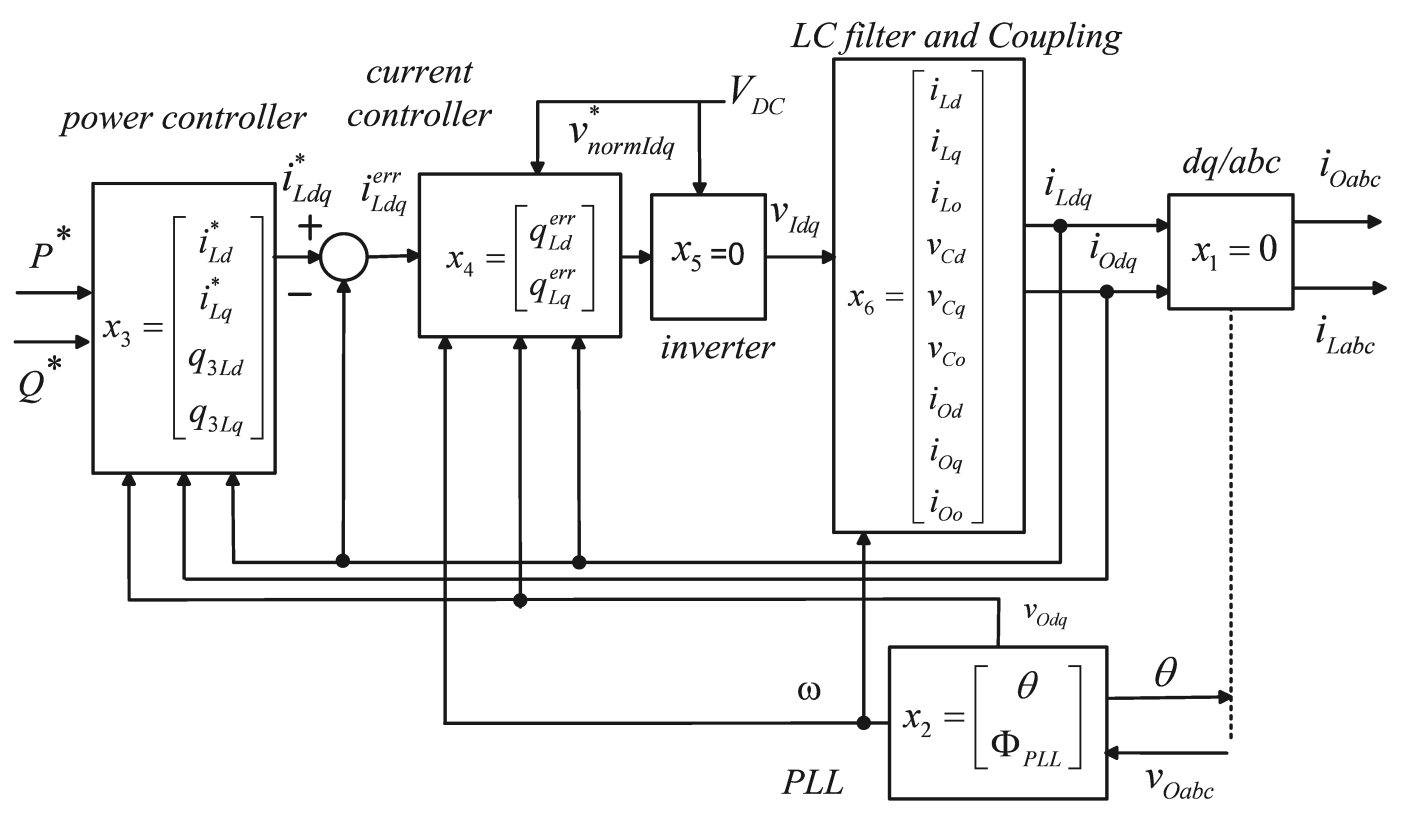

Figure 7: Topology of a current controlled inverter with the state vectors of each subsystem

The state variables also need to be combined into a single state vector as given by (30). The first two state variables, $\theta$ and $\Phi_{\mathrm{PLL}}$, are contributed by the PLL system. Four state variables arise from the two second-order Butterworth filters in the power controller: $i_{L d}^{*}, i_{L q}^{*}, q_{3 d}, q_{3 q}$. Variables $q_{L d}^{\mathrm{err}}$ and $q_{L q}^{\mathrm{err}}$ are the result of the integrators in the current controller. The states $i_{L d}, i_{L q}, i_{L_{O}}, v_{C d}, v_{C q}, v_{C_{O}}$ appear due to the reactive elements of LC filter and, finally, $i_{O d}, i_{O q}$ and $i_{O_{O}}$ are contributed by the coupling reactance.

$x_{\mathrm{CCI}}=\left[\begin{array}{lllllllllllllllll}\theta & \Phi_{\mathrm{PLL}} & i_{L d}^{*} & i_{L q}^{*} & q_{3 L d} & q_{3 L q} & q_{L d}^{\mathrm{err}} & q_{L q}^{\mathrm{err}} & i_{L d} & i_{L q} & i_{L_{O}} & v_{C d} & v_{C q} & v_{C O} & i_{O d} & i_{O q} & i_{O O}\end{array}\right]^{T}$

Matrix $A_{\mathrm{CCI}}$ for the whole system is obtained by combining together the $A$ matrices of the PLL, the power controller, the current controller and the LC filter. This is because these four subsystems are the only ones with state variables in their models. Equation (31) illustrates how the matrices are combined.

$$
A_{\mathrm{CCI}}=\left[\begin{array}{cccc}
{\left[A_{2}\right]} & 0 & 0 & 0 \\
0 & {\left[A_{3}\right]} & 0 & 0 \\
0 & 0 & {\left[A_{4}\right]} & 0 \\
0 & 0 & 0 & {\left[A_{6}\right]}
\end{array}\right]
$$

There are several simplifications to be made to the resulting matrix $A_{\mathrm{CCI}}$ to make it more compact. The inductor currents and their reference values occur in several places in the model such as in the error terms of the current controllers and as state variables in the power regulator. Furthermore, they are integrated to provide further state 
variables. The terms in $A_{3}$ and $A_{4}$ and in $R_{3}$ and $B_{4}$ can be simplified on combination to $A_{34}$ and $R_{34}$ as shown in (32)

$$
\begin{aligned}
& \dot{x}_{34}=\left[\begin{array}{cccccc}
-\sqrt{2} \omega_{c} & 0 & \omega_{c}^{2} & 0 & 0 & 0 \\
0 & -\sqrt{2} \omega_{c} & 0 & \omega_{c}^{2} & 0 & 0 \\
-1 & 0 & 0 & 0 & 0 & 0 \\
0 & -1 & 0 & 0 & 0 & 0 \\
1 & 0 & 0 & 0 & 0 & 0 \\
0 & 1 & 0 & 0 & 0 & 0
\end{array}\right]\left[\begin{array}{c}
i_{L d}^{*} \\
i_{L q}^{*} \\
q_{3 d} \\
q_{3 q} \\
q_{L d}^{e r r} \\
q_{L q}^{e r r}
\end{array}\right]+R_{34}\left(u_{34}\right) \\
& R_{34}\left(u_{34}\right)=\left[\begin{array}{c}
0 \\
0 \\
\frac{v_{O d} P^{*}-v_{O q} Q^{*}}{v_{O d}^{2}+v_{O q}^{2}}+i_{L d}-i_{O d} \\
\frac{v_{O q} P^{*}+v_{O d} Q^{*}}{v_{O d}^{2}+v_{O q}^{2}}+i_{L q}-i_{O q} \\
-i_{L d} \\
-i_{L q}
\end{array}\right]
\end{aligned}
$$

Furthermore, examination of $R_{34}\left(u_{34}\right)$ reveals that $i_{L d q}$ and $i_{O d q}$ are states of one of the other sub-systems and so terms associated with them should appear in the $A_{\mathrm{CCI}}$ matrix of the complete system. Incorporating these modifications into (31) gives the complete matrix $A_{\mathrm{CCI}}$ defined in (34) for the current-controlled inverter. The non-linear dependencies found in the inverter system model, such as products of states, and the input terms are collected in $R_{\mathrm{CCI}}\left(x_{\mathrm{CCI}}, u_{\mathrm{CCI}}\right)$ as summarised in (35). An important non-linearity to consider is in the calculation of the terms $v_{I d}$ and $v_{I q}$ which includes the possible application of the saturation limit. 


$$
A_{\text {CCI }}=\left[\begin{array}{ccccccccccccccccc}
0 & K_{I}^{P L L} & 0 & 0 & 0 & 0 & 0 & 0 & 0 & 0 & 0 & 0 & 0 & 0 & 0 & 0 & 0 \\
0 & 0 & 0 & 0 & 0 & 0 & 0 & 0 & 0 & 0 & 0 & 0 & 0 & 0 & 0 & 0 & 0 \\
0 & 0 & -\sqrt{2} \omega_{c} & 0 & \omega_{c}^{2} & 0 & 0 & 0 & 0 & 0 & 0 & 0 & 0 & 0 & 0 & 0 & 0 \\
0 & 0 & 0 & -\sqrt{2} \omega_{c} & 0 & \omega_{c}^{2} & 0 & 0 & 0 & 0 & 0 & 0 & 0 & 0 & 0 & 0 & 0 \\
0 & 0 & -1 & 0 & 0 & 0 & 0 & 0 & 1 & 0 & 0 & 0 & 0 & 0 & -1 & 0 & 0 \\
0 & 0 & 0 & -1 & 0 & 0 & 0 & 0 & 0 & 1 & 0 & 0 & 0 & 0 & 0 & -1 & 0 \\
0 & 0 & 1 & 0 & 0 & 0 & 0 & 0 & -1 & 0 & 0 & 0 & 0 & 0 & 0 & 0 & 0 \\
0 & 0 & 0 & 1 & 0 & 0 & 0 & 0 & 0 & -1 & 0 & 0 & 0 & 0 & 0 & 0 & 0 \\
0 & 0 & 0 & 0 & 0 & 0 & 0 & 0 & \frac{-R}{L} & 0 & 0 & \frac{-1}{L} & 0 & 0 & 0 & 0 & 0 \\
0 & 0 & 0 & 0 & 0 & 0 & 0 & 0 & 0 & \frac{-R}{L} & 0 & 0 & \frac{-1}{L} & 0 & 0 & 0 & 0 \\
0 & 0 & 0 & 0 & 0 & 0 & 0 & 0 & 0 & 0 & \frac{-3 R_{G}-R}{L} & 0 & 0 & \frac{-1}{L} & 0 & 0 & \frac{3 R_{G}}{L} \\
0 & 0 & 0 & 0 & 0 & 0 & 0 & 0 & \frac{1}{C} & 0 & 0 & 0 & 0 & 0 & \frac{-1}{C} & 0 & 0 \\
0 & 0 & 0 & 0 & 0 & 0 & 0 & 0 & 0 & \frac{1}{C} & 0 & 0 & 0 & 0 & 0 & \frac{-1}{C} & 0 \\
0 & 0 & 0 & 0 & 0 & 0 & 0 & 0 & 0 & 0 & \frac{1}{C} & 0 & 0 & 0 & 0 & 0 & \frac{-1}{C} \\
0 & 0 & 0 & 0 & 0 & 0 & 0 & 0 & 0 & 0 & 0 & \frac{1}{L_{\text {coupl }}} & 0 & 0 & \frac{-R_{\text {coupl }}}{L_{\text {coupl }}} & 0 & 0 \\
0 & 0 & 0 & 0 & 0 & 0 & 0 & 0 & 0 & 0 & 0 & 0 & \frac{1}{L_{\text {coupl }}} & 0 & 0 & \frac{-R_{\text {coupl }}}{L_{\text {coup }}} & 0 \\
0 & 0 & 0 & 0 & 0 & 0 & 0 & 0 & 0 & 0 & 0 & 0 & 0 & \frac{-3 R_{G}}{L_{\text {coupl }}} & 0 & 0 & \frac{-3 R_{G}-R_{\text {coupl }}}{L_{\text {coupl }}}
\end{array}\right]
$$

$$
R_{\mathrm{CCI}}\left(x_{C C I}, u_{C C I}\right)=\left[\begin{array}{c}
K_{P}^{\mathrm{PLL}} v_{O q} \\
v_{O q} \\
0 \\
0 \\
\frac{v_{O d} P^{*}-v_{O q} Q^{*}}{v_{O d}^{2}+v_{O q}^{2}} \\
\frac{v_{O Q} P^{*}+v_{O d} Q^{*}}{v_{O d}^{2}+v_{O q}^{2}} \\
0 \\
0 \\
\frac{1}{L} v_{I d}+\omega i_{L q} \\
\frac{1}{L} v_{I q}-\omega i_{L d} \\
0 \\
\omega v_{C q} \\
-\omega v_{C d} \\
0 \\
-\frac{1}{L_{\text {coupl }}} v_{O d}+\omega i_{O q} \\
-\frac{1}{L_{\text {coupl }}} v_{O q}-\omega i_{O d} \\
0 \\
0
\end{array}\right]
$$

The final task is to assemble the output vector for (1) which will normally be composed of the output currents. To aid verification of the model, the filter inductor currents have also been included. These variables are in $a b c$ form and so are computed as a function of both the corresponding state variables in $d q$ form and the state variable representing the angle of the $d q$-abc transformation as described in (2). The DC link current could be added to this vector and (by assuming the inverter itself is power conserving) calculated as an algebraic manipulation of the normalised inverter voltages and the inductor currents. 


$$
y_{\mathrm{CCI}}=\left[\begin{array}{llllll}
i_{L a} & i_{L b} & i_{L c} & i_{O a} & i_{O b} & i_{O c}
\end{array}\right]^{T}
$$

\section{Validation Examples}

The state-space model relies on the development of many supporting equations and some modelling assumptions. To verify the state-space model, solutions generated by it were compared to solutions from a component and block level simulation in Simulink. The PLECS toolbox for Simulink was used to give component-level simulation of power electronic devices and other circuit elements. Both the state-space and Simulink models were set up with the parameters shown in Table 2 .

\begin{tabular}{|c|c|c|}
\hline \multicolumn{2}{|c|}{ Parameter } & Value \\
\hline \multicolumn{2}{|c|}{ Nominal Phase Voltage } & $240 \mathrm{~V}$ \\
\hline \multicolumn{2}{|c|}{ Grid Frequency } & $50 \mathrm{~Hz}$ \\
\hline \multicolumn{2}{|c|}{ Coupling impedance } & $(0.131+j \omega 0.96) \Omega$ \\
\hline \multicolumn{2}{|c|}{ DC Bus Voltage } & $1000 \mathrm{~V}$ \\
\hline \multirow{3}{*}{ Filter } & Inductance & $1.35 \mathrm{mH}$ \\
\hline & Capacitance & $50 \mu \mathrm{F}$ \\
\hline & Resistance & $0.056 \Omega$ \\
\hline \multicolumn{2}{|c|}{ Switching Frequency } & $8 \mathrm{kHz}$ \\
\hline \multicolumn{2}{|c|}{ Reference active power } & $10 \mathrm{~kW}$ \\
\hline \multicolumn{2}{|c|}{ Reference reactive power } & $5 \mathrm{k} \operatorname{Var}$ \\
\hline \multirow{4}{*}{$\begin{array}{l}\text { current } \\
\text { controller }\end{array}$} & Proportional gain in branch $d K_{P}^{d}$ & 1 \\
\hline & Integral gain in branch $d K_{I}^{d}$ & 460 \\
\hline & Proportional gain in branch $q K_{P}^{q}$ & 1 \\
\hline & Integral gain in branch $q K_{I}^{q}$ & 460 \\
\hline \multirow[b]{2}{*}{ PLL } & Proportional gain $K_{P}$ & 2.1 \\
\hline & Integral gain $K_{I}$ & 5000 \\
\hline
\end{tabular}

Table 2: Simulation Setup

\subsection{Numerical Solution of the State-Space Model}

The state-space model can be used within general simulation systems or power-system specific software. For this validation it was explicitly solved using numerical integration in a Matlab script. There are several integration methods available for solving differential-algebraic equations. The partitioned-explicit solution method is chosen here since there is not a need to examine dynamics over a wide range of time-scales. The simultaneous implicit 
solution would be preferred for that case [27]. The PE solution was implemented in MATLAB scripts using an explicit $4^{\text {th }}$-order Runge-Kutta formula.

\subsection{Component-Level Comparator Model}

Fig. 8 shows the overall Simulink model of the grid-connected inverter. The "PLL", "Power Controller" and "Current control" correspond to figs. 2, 3 and 4, respectively. The block "abc to dq" implements the $d q$ transformation given in (4), and the block "SVM" contains a MATLAB script which produces the power transistor gate signals from 2-axis voltages in the a stationary reference frame $\left(v_{\alpha}\right.$ and $\left.v_{\beta}\right)$ using the Space Vector Modulation (SVM) technique. (The SVM process and the transistor switching action were explicitly excluded from the the state-space model.) The gate signals are then applied to an inverter circuit created in the PLECS extension to Simulink as shown in Fig. 9.

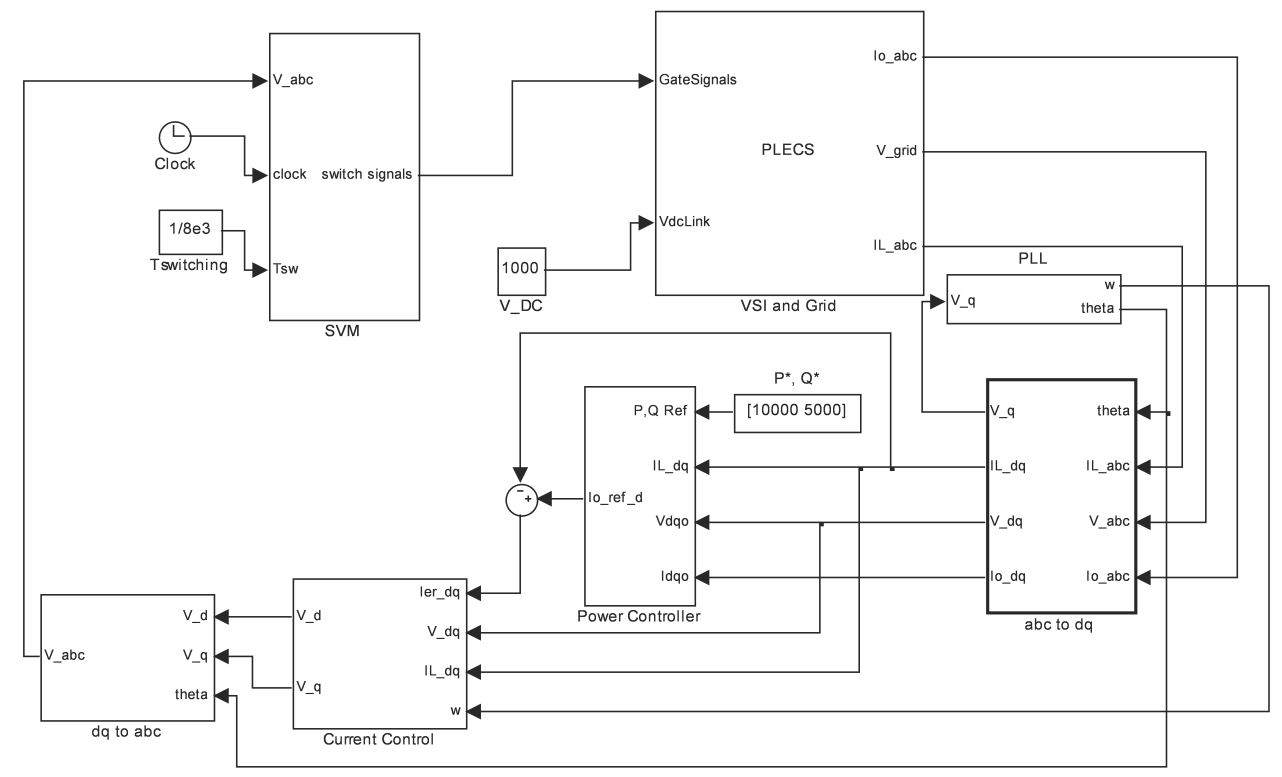

Figure 8: SIMULINK model of current controlled voltage source inverter with its ancillary circuits

\section{Comparison of Results}

\subsection{Initial transient}

At start up there is an initial transient as the controllers act to established the requested power flow. Both models were given power references of $P^{*}=10 k W, Q^{*}=5 k V A r$. The inductor currents in $a b c$ form are shown in 


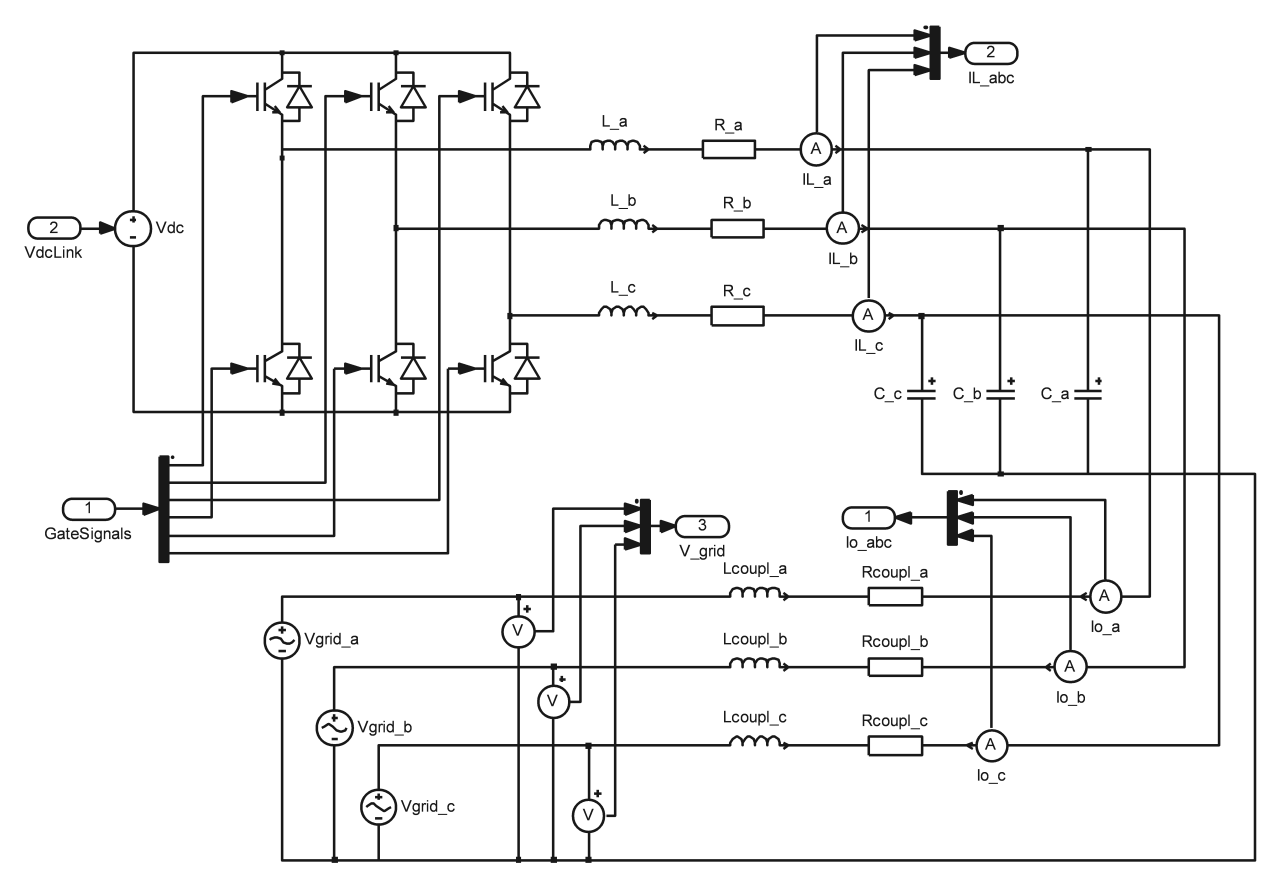

Figure 9: PLECS model of inverter, LC filter and coupling impedance

fig. 10a. The upper graph shows the results from the PLECS/Simulink model and the lower graph shows those from the state-space model. It is clear that both the initial transient and steady-state sinusoidal currents present the sameevolution in time in each case, but that the Simulink model has a high frequency ripple superimposed on the basic current waveform. This is the ripple arising from the switching action of the inverter and was explicitly excluded from the state-space model.
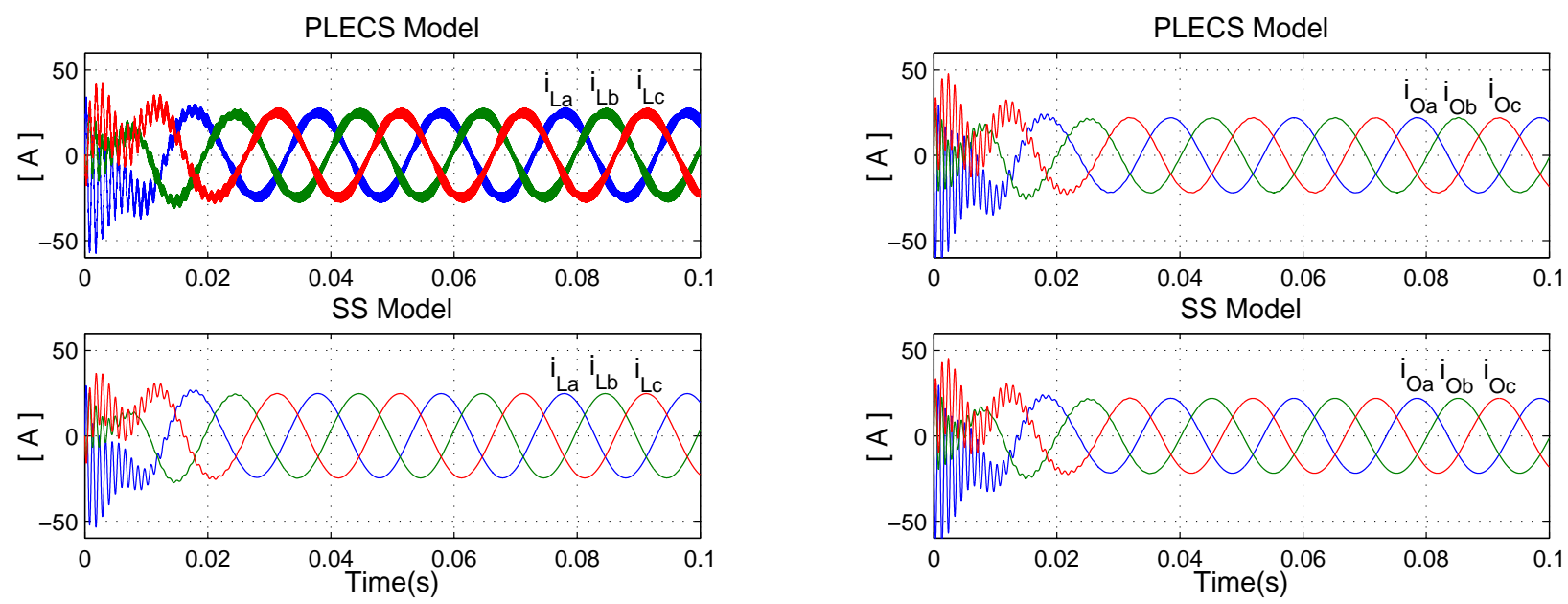

(a)

(b)

Figure 10: Behaviour during the initial transient in the $a b c$ reference frame: (a)inductor currents, (b)output currents 
The inductor currents are internal states and will not normally be used as outputs of the model in a system study. Fig. 10b shows the output currents, that is the currents that flow in the grid connection (again in $a b c$ form); here the PLECS/Simulink results show very little switching frequency ripple because the $L C$ filter has attenuated these components. This justifies the argument presented in section 2.5 that, at the connection point, the switching ripple is relatively small and in most cases it can be neglected. The lower graph in fig. 10b confirms that the statespace model gives an accurate representation of the system. The output powers from both models are presented in fig. 11 and again show good agreement.
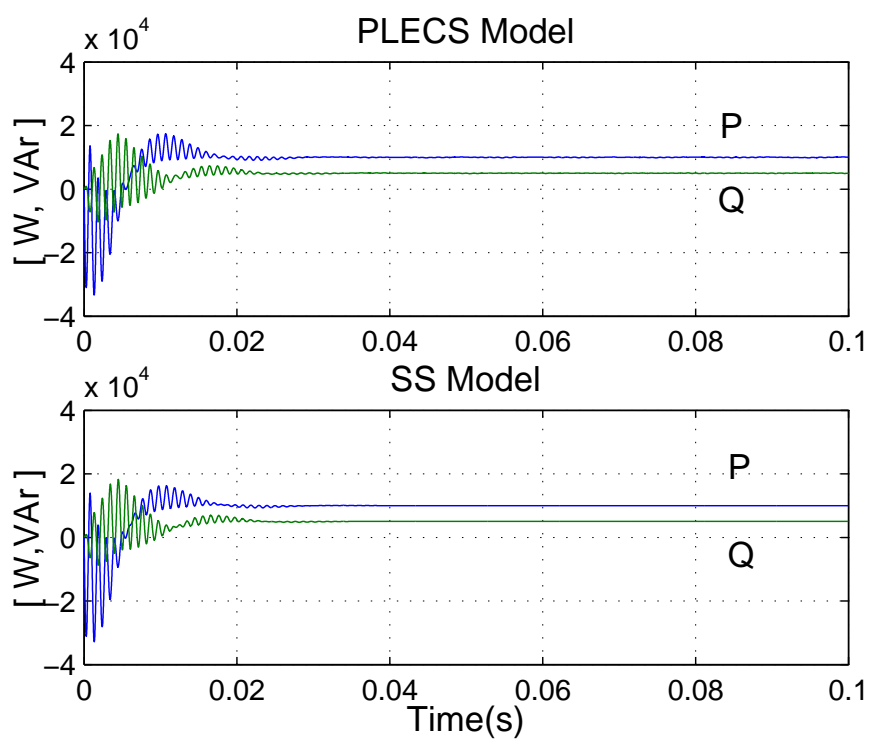

Figure 11: Output power

\subsection{Step change in load}

A series of further tests were conducted to illustrate the sort of study that the state-space model facilitates. The response of the inverter to changes in power reference is an important performance criterion. Here it was tested with a series of step changes. The initial reference values of the active and reactive powers were $10 \mathrm{~kW}$ and $5 \mathrm{kVAr}$. The active power was stepped up to $20 \mathrm{~kW}$ at $0.1 \mathrm{~s}$ and stepped down to $10 \mathrm{~kW}$ at $0.4 \mathrm{~s}$. The reactive power was increased to $2 \mathrm{kVAr}$ at $0.2 \mathrm{~s}$ and to $5 \mathrm{kVAr}$ at $0.5 \mathrm{~s}$. The resulting output powers of the system together with the reference powers are shown in fig. 12 (the initial 0.05 s containing the start-up transient is not shown). It can be seen that the response to the changes in reference values is fast and without significant overshoot but that there is some coupling between active and reactive power (for example the step change of active power at 0.1 results in a negative excursion in reactive power) which might be tackled through changes to the current controller. 

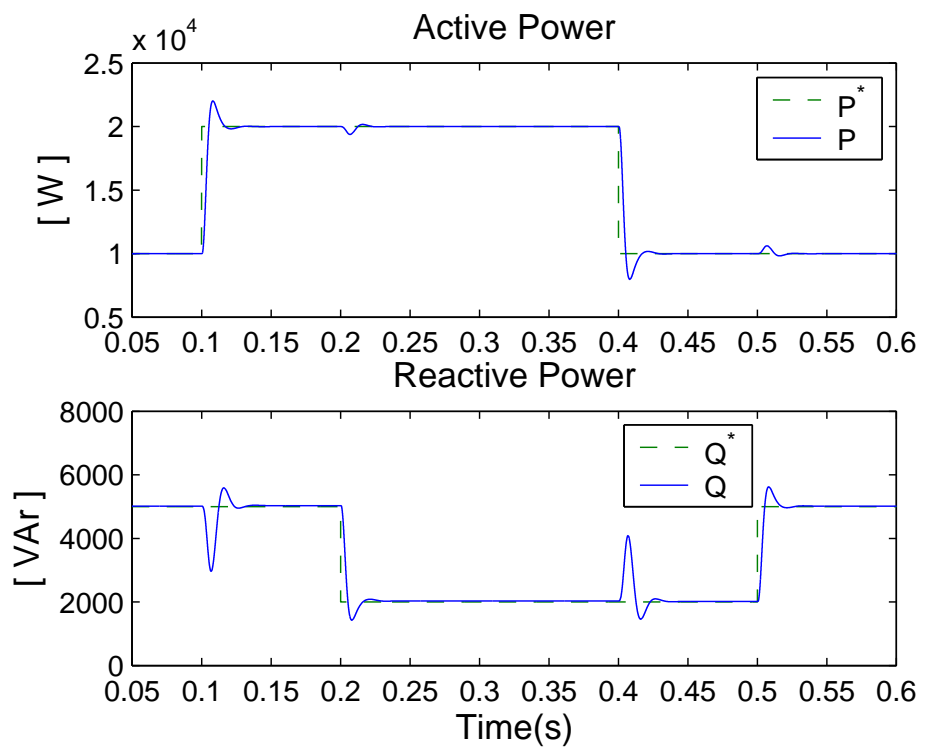

Figure 12: Reference and actual active and reactive power

\section{Conclusions}

An appropriate level of detail is needed in a model for each purpose to which it is put. A state-space model has been presented that enables transient stability of a grid connected inverter to be studied. The model is in state-space form and specifically avoids simulation of switching frequency effects. It has been shown to capture the important dynamics of the passive output filter, the current controllers, the filter in the power reference to current reference conversion and the controller that establishes phase-locking. This phase-locked and current-controlled form of inverter is common for distributed generators connected to relatively strong grids. The model has been built up in stages, or sub-systems, so that it can be related to practical implementations of inverters. The state-space form allows coupling of this model to standard models of distribution grids and coupling of several inverters in one system. The state vector has a similar form to the state vector of standard models of rotating machines. Thus, full dynamic models of complex systems can be built and stability of the system assessed through either time-domain technique or, after linearisation, frequency-domain techniques. The model can also be coupled to models of the original DC energy source through the DC-link port provided. Participation analysis will allow identification of which inverter features influence which oscillatory modes of a system. Through experience with various inverter implementations it will be possible to establish general rules for enhancing the stability of networks that include inverter-interfaced DG. 


\section{References}

[1] A. Agbossou, I. Rasoanarivo, and B. Davat, "A comparative study of high power IGBT model behaviour in voltage source inverter," in IEEE 27th Annual Power Electronics Specialist Conference (PESC), vol. 1, 1996, pp. $56-61$.

[2] Z. Mihailovic, H. Prasad, and D. Borojevic, "Computer modeling and analysis of vsi fed permanent magnet synchronous motor drive systems with adjustable levels of complexity," in 12th Annual Applied Power Electronics Conference and Exposition (APEC), vol. 2, Atlanta, GA, 1997, pp. 728 - 735.

[3] L. Salazar and G. Joos, "Pspice simulation of three-phase inverters by means of switching functions," IEEE Transactions on Power Electronics, vol. 9, no. 1, pp. 35-42, 1994.

[4] B. Lee and M. Ehsani, "A simplified functional model for 3-phase voltage source inverter using switching function concept," in The 25th Annual Conference of Industrial Electronics Society (IECON), vol. 1, San Jose, CA, 1999, pp. $462-467$.

[5] J. Alimeling and W. Hammer, "Plecs-piece-wise linear electrical circuit simulation for simulink," in Proceedings of the IEEE 1999 International Conference on Power Electronics and Drive Systems, vol. 1. IEEE, 1999, pp. $355-360$.

[6] J. G. Kassakian, M. F. Schlecht, and G. C. Verghese, Principles of power electronics. Addison-Wesley, 1991.

[7] D. Karagiannis, E. Mendes, A. Astolfi, and R. Ortega, "An experimental comparison of several PWM controllers for a single-phase AC-DC converter," Control Systems Technology, IEEE Transactions on, vol. 11, pp. 940-947, 2003.

[8] S. Hiti, D. Boroyevich, and C. Cuadros, "Small-signal modeling and control of three-phase PWM converters," in Industry Applications Society Annual Meeting, vol. 2, 1994, pp. 1143 - 1150.

[9] V. Blasko and V. Kaura, "A new mathematical model and control of a three-phase AC-DC voltage source converter," IEEE Transactions on Power Electronics, vol. 12, no. 1, pp. 116 - 123, 1997.

[10] P. Lehn, "Exact modeling of the voltage source converter," Power Delivery, IEEE Transactions on, vol. 17, no. 1 , pp. $217-222,2002$.

[11] J. Bordonau, M. Cosan, D. Borojevic, H. Mao, and F. Lee, "A state-space model for the comprehensive dynamic analysis of three-level voltage-source inverters," in IEEE 28th Annual Power Electronics Specialists Conference, vol. 2, St. Louis, MO, 1997, pp. $942-948$.

[12] N. Celanovic, D.-H. Lee, D. Peng, D. Borojevic, and F. Lee, "Control design of three-level voltage source inverter for SMES power conditioning system," in IEEE 30th Annual Power Electronics Specialists Conference (PESC), vol. 2, Charleston, SC, 1999, pp. $613-618$.

[13] C. Fritsche, P. Schmitt, and C. Gerster, "Microprocessor-based control system for high-speed three-phase voltage source inverters with lc output filter," in IEEE 30th Annual Power Electronics Specialists Conference (PESC), vol. 1, Charleston, SC, 1999, pp. $527-532$. 
[14] S. Alepuz, A. Gilabert, E. Arguelles, J. Bordonau, and J. Peracaula, "A new approach for the connection of a three-level inverter to the power grid for applications in solar energy conversion," in IEEE 28th Annual Conference of the Industrial Electronics Society (IECON), vol. 4, 2002, pp. 3285 - 3290.

[15] B. Han, G. Karady, J. Park, and S. Moon, "Interaction analysis model for transmission static compensator with EMTP," IEEE Transactions on Power Delivery, vol. 13, no. 4, pp. 1297 - 1302, 1998.

[16] N. Abdel-Rahim and J. Quaicoe, "Small-signal model and analysis of a multiple feedback control scheme for three-phase voltage-source UPS inverters," in IEEE 27th Annual Power Electronics Specialists Conference (PESC), vol. 1, Baveno, 1996, pp. $188-194$.

[17] P. Lehn and M. Irvani, "Discrete time modeling and control of the voltage source converter for improved disturbance rejection," IEEE Transactions on Power Electronics, vol. 14, no. 6, pp. 1028 - 1036, 1999.

[18] S. Alepuz, J. Bordonau, and J. Peracaula, "Dynamic analysis of three-level voltage-source inverters applied to power regulation," in IEEE 30th Annual Power Electronics Specialists Conference, vol. 2, Charleston, SC, 1999, pp. $721-726$.

[19] ——, "A novel control approach of three-level VSIs using a LQR-based gain-scheduling technique," in Power Electronics Specialists Conference, 2000. PESC 00. 2000 IEEE 31st Annual, vol. 2, 2000, pp. 743-748 vol.2.

[20] J. Guerrero, L. de Vicuna, J. Matas, M. Castilla, and J. Miret, "A wireless controller to enhance dynamic performance of parallel inverters in distributed generation systems," IEEE Transactions on Power Electronics, vol. 19, no. 5, pp. $1205-1213,2004$.

[21] N. Kroutikova, C. Hernandez-Aramburo, and T. Green, "State space model of voltage controlled inverters for distributed energy resources," Companion paper under review, 2006.

[22] M. Prodanovic and T. Green, "Control and filter design of three-phase inverters for high power quality grid connection," IEEE Transactions on Power Electronics, vol. 18, no. 1, pp. 373 - 380, 2003.

[23] M. Prodanovic, "Power quality and control aspects of parallel connected inverters in distributed generation," Ph.D. dissertation, University of London, Imperial College, January 2004.

[24] V. Kaura and V. Blasko, "Operation of a phase locked loop system under distorted utility conditions," in Proceedings of the Annual Applied Power Electronics Conference, vol. 2. IEEE, April 1996, pp. 703 - 708.

[25] M. Liserre, F. Blaabjerg, and S. Hansen, "Design and control of an lcl-filter-based three-phase active rectifier," IEEE Transactions on Industry Applications, vol. 41, no. 5, pp. 1281 - 1291, 2005.

[26] B. Bolsens, K. De Brabandere, J. Van den Keybus, J. Driesen, and R. Belmans, "Model-based generation of low distortion currents in grid-coupled pwm-inverters using an lcl output filter," IEEE Transactions on Power Electronics, vol. 21, no. 4, pp. 1032-1040, 2006.

[27] P. W. Sayer and M. Pai, Power system dynamics and stability. New Jersey: Prentice Hall, 1998. 